\title{
Introduction to the Special Issue: International Law for the Sustainable Development Goals
}

This special issue on International Law for the Sustainable Development Goals has a rich history to it, and a few thoughts should be shared in this regard. The papers included in this special issue resulted from a workshop series on the theme of International Law for the Sustainable Development Goals, organised by the Department of Transboundary Legal Studies at the Faculty of Law, University of Groningen between May 2017 and February 2019. The series built on a prior seminar series organised by what was formerly known as the Department of International Law in 2013-2014, on Human Rights and Essential Public Services Provision. ${ }^{1}$ This time, we set out to explore, with colleagues, researchers, academics and practitioners from various disciplines, the role, relevance, potential and limitations of public international law for the implementation of the 17 United Nations Sustainable Development Goals (SDGs). ${ }^{2}$

\section{Looking Back at the Workshop Series on International Law for the SDGS}

The workshop series explored, over two years and eight workshops, the following themes and topics: ${ }^{3}$

- Special opening lecture (Avril McDonald Memorial Lecture): Sharing our Earth: International Law and the Sustainable Development Goals, by Professor Dr Joyeeta Gupta (May 2017);

- Workshop 1: Sustainable Development Goals: Prospects \& Challenges? (May 2017);

1 See M. Hesseleman, A. Hallo de Wolf and B. Toebes (eds.), Socio-Economic Rights in Essential Public Services Provision (Abingdon: Routledge 2017).

2 UNGA Res. A/RES/70/1, Transforming Our World: the 2030 Agenda for Sustainable Development, 21 October 2015.

3 The detailed programme for the workshops, including concept notes, are available at the series' webpage, https://www.rug.nl/rechten/congressen/il4sdgs, accessed ${ }_{15}$ September 2019.

(C) RACHOVITSA AND HESSELMAN, 2019 | DOI:10.1163/23527072-20191031

This is an open access article distributed under the terms of the prevailing CC-BY license at the time of publication. 
- Workshop 2: Financing the SDGs \& the Right to Science in Technology Transfer in the SDGs (SDG 17) (November 2017);

- Workshop 3: International Law and Accountable, Transparent Institutions (sDG 16) (January 2018);

- Workshop 4: Gender, Health and Sustainable Development: The Role for International Human Rights Law (SDGs 3 and 5) (May 2018);5

- Workshop 5: The Role of Industries in the Global Increase of Chronic Diseases, such as Cancers, Heart Diseases and Diabetes (SDG 3) (June 2018); 6

- Workshop 6: Corruption, Human Rights and the SDGs (SDG 16) (September 2018);

- Workshop 7: Sustainable, Safe and Resilient Urban Settlements: The Right to the City \& Urban Inclusivity (SDG 11) (October 2018); and

- Workshop 8: Renewable Energy in the sDGs: Barriers, Opportunities, Interaction (SDG 7) (February 2019). ${ }^{7}$

We had the great pleasure of hosting many legal scholars and experts from other disciplines working in the UK, USA, Pakistan, South Africa, Uganda, Nigeria, Indonesia, Belgium, Poland, Italy, Hungary, Ireland, Luxembourg, Germany, the Czech Republic, Denmark and, of course, colleagues from the Netherlands (including the universities of Utrecht, Maastricht, Amsterdam, Tilburg and Leiden, the Erasmus University of Rotterdam and the Asser Institute). In the spirit of the SDGs, we brought together and engaged with nonacademic stakeholders, including industry, practitioners, civil society and policymakers. These were:Luxembourg Investment Solutions (Luxembourg and Ireland); Sagar Energy Solutions (Réunion, France); the Office of the Ombudsman for Future Generations (Hungary); the Centre for Health, Human Rights and Development (Uganda); Obafemi Adewale \& Co. (Nigeria); the Institute of Development Research and Development Policy (Ruhr-University Bochum, Germany); AquaBattery (Netherlands); the Dutch Institute for Human Rights;

4 The workshop was organised by Dr Lottie Lane (Assistant Professor of International Law, Faculty of Law, University of Groningen).

5 The workshop was co-organised by Dr Lucía Berro Pizzarossa (post-doctoral researcher, University of Groningen) and Dr Katrina Perehudoff (post-doctoral researcher, International Centre for Reproductive Health, Ghent University).

6 The workshop was co-organised by Dr Marie Elske Gispen, Dr Katrina Perehudoff and Dr Lottie Lane. The event formed part of the conference on Law and Noncommunicable Diseases organised by the European Scientific Network on Law and Tobacco, led by the Global Health Law Groningen Research Centre, the University of Groningen and the Leuven Institute for Healthcare Policy and Leuven Centre for Public Law, KU Leuven.

7 This workshop was co-organised by Lea Diestelmeier ( $\mathrm{PhD}$ researcher, Groningen Centre of Energy Law) and Ceciel Nieuwenhout (PhD researcher, Groningen Centre of Energy Law). 
the Dutch Cancer Society; the Regulatory Science Network Netherlands; Medicines Law \& Policy; the Dutch Heart Foundation; and Transparency International (Netherlands section). As far as the University of Groningen is concerned, we were delighted to host on our workshop panels colleagues not only from the Faculty of Law but also from the Faculty of Arts; the Global Health Law Groningen Research Centre; the European Scientific Network on Law and Tobacco; the Groningen Centre of Energy Law; the Centre for Religion, Health and Well-Being; and Campus Fryslân.

The papers included in the special issue are:

- 'A Rough Trade’? Towards A More Sustainable Minerals Supply Chain, by Daniëlla Dam-de Jong;

- Can A Transnational Law Approach Offer A Better Understanding of International Law's Contribution to Sustainable Hydropower Projects? A Test Case from the Mekong River Basin, by Laure-Elise Mayard;

- Implementing the SDG-13 Through the Adoption of Hybrid Law: Addressing Climate-induced Displacement, by Stellina Jolly and Abhishek Trivedi;

- Liberalizing the Global Supply Chain of Renewable Energy Technology: The Role of International Investment Law in Facilitating Flows of Foreign Direct Investment and Trade, by Cees Verburg and Jaap Waverijn; and

- Where Economic Development Meets the Rule of Law? Promoting Sustainable Development Goals Through the European Neighbourhood Policy, by Maryna Rabinovych.

On the basis of the discussions that took place during the workshops, and by way of consolidating certain key underlying commonalities observed in the papers of the special issue, we note below certain shared themes and questions that emerge when discussing the role, relevance, potential and limitations of public international law in relation to the SDGs.

\section{The SDGs as a Reason to Rethink International Law?}

Enquiring into the relevance and role of international law for the SDGs brings to the forefront questions about the suitability and capacity of international law to support (specific objectives of) the SDGs: What is international law for? Does international law have (and if not, can it develop) the capacity to support 
the realisation of sustainable development? The SDGs as a policy document may encapsulate an integrated vision for sustainable development and declare the need for institutional and policy coherence (SDG 17). Yet, what is to be expected from a compartmentalised or fragmented international law? Is the concept of sustainable development, as proposed in the SDG agenda, as coherent and clear as would have been expected?

On the latter aspect, it is of interest that none of the authors actually derives from the SDGs a singular definition of sustainable development towards which international law should strive or contribute. At the same time, each of the papers refers to what seems to be a 'fourth pillar' for sustainable development, as reflected in SDG 16: a pillar of (legal) security or stability. Rabinovic, Maynard, Jolly \& Trivedi, De Jong and Waverijn \& Verburg, each in their own way, emphasise that attaining sustainable development is dependent on the rule of law, peace, stability, transparency, accountability, security and the absence of conflict. It will be crucial to explore, in future research, what the role of SDG 16 is in relation to sustainable development as a whole and with regard to questions of policy coherence or integration specifically.

The two papers by Jolly \& Trivedi $^{8}$ and Mayard, ${ }^{9}$ respectively, proclaim at the outset that international law's traditional framework is limited and arguably ill equipped to fully grasp the challenges of implementing the SDGS, including challenges relating to an increasingly complex landscape of stakeholders and legal regimes. Both papers argue for a broader conceptualisation of international law, so that international law becomes more responsive to pluralistic regulation and a diversification of players, interests and legal regimes. Jolly \& Trivedi address climate-induced displacement and SDG 13 by applying a hybrid law approach, whereas Mayard employs a transnational law approach to the regulation of the Mekong River Basin, as a test case study for hydropower projects.

\section{Understanding Shared Objectives of the SDGs and International} Law: Defining Terms and Forcing Links

Inevitably, most authors started their enquiries into the possible role, relevance, contribution, potential or limitations of international law for the SDGs

8 Stellina Jolly and Abhishek Trivedi, 'Implementing the SDG-13 Through the Adoption of Hybrid Law: Addressing Climate-induced Displacement' (infra special issue).

9 Laure-Elise Mayard, 'Can A Transnational Law Approach Offer A Better Understanding of International Law's Contribution to Sustainable Hydropower Projects? A Test Case from the Mekong River Basin' (infra special issue). 
by seeking to clarify key terms in the SDGs or in international law, and by exploring or even forcing relevant links between these two international 'agendas'. The normative appeal and versatility of the SDG agenda seems underscored by the fact that throughout the workshop series contributors sought and managed to draw connections between international law and many SDGs, including on topics not even explicitly listed amongst the SDGs as such. In this special issue, the papers by Jolly \& Trivedi (on climate displacement) and De Jong (on illicit mineral trade) are examples of authors apparently seeing a conceptual or practical merit in exploring international law and the SDGs in conjunction. This raises the question of what is the normative appeal or benefit of mapping international law questions onto specific SDGs or the SDG agenda as a whole? Or perhaps vice versa, what is the benefit or normative appeal of using the SDGs to capture or address unresolved questions of international law and legal practice?

The following section briefly revisits this question, but here we chiefly observe a striking aspect of the papers, which is that nearly all of them also turn to (legal) theory in reflecting on the objectives shared between international law and the SDGs. De Jong, for example, tackles the meaning of effective, accountable and transparent institutions at all levels as promoted by SDG 16.6 in the context of trade in natural resources that finance armed conflict. ${ }^{10}$ She examines how, in this context, the vague notions of transparency and accountability are conceptualised in international legal discourse and accountability theory, and are applied in practice through the Kimberley Process for the Certification of Rough Diamonds and the OECD Due Diligence Guidance for Responsible Supply Chains of Minerals from Conflict-affected and High-risk Areas. She concludes that existing frameworks may still fall short of fostering particular forms of accountability or transparency, but that, overall, these initiatives appear valuable (first) steps towards the broader aims of SDG 16 in terms of fostering 'peaceful societies for sustainable development'. Rabinovych takes as her starting point the interlinkages between economic development (SDG 8) and the rule of law (SDG 16). ${ }^{11}$ In unpacking the postulate of 'peace through economic development and legal integration' for her case study of the eastern dimension of the European Neighbourhood Policy, she proceeds to use leading post-war development economics theories to reflect on the meaning of key terms such as the 'rule of law' or 'sustainable development'. Rabinovych

\footnotetext{
10 Daniëlla Dam de Jong, "'A Rough Trade”? Towards A More Sustainable Minerals Supply Chain' (infra special issue).

11 Maryna Rabinovych, 'Where Economic Development Meets the Rule of Law? Promoting Sustainable Development Goals Through the European Neighbourhood Policy' (infra special issue).
} 
finds not only that the SDGs do not provide a conceptually clear vision of the role of economic development and legal integration in development, but also that selectiveness and inconsistencies are entrenched in international law and theory and EU law and policy.

While not explicitly addressed in these papers, efforts to understand the role, relevance, potential and limitations of international law in relation to the SDGs, through a range of additional theories and concepts, raise interesting questions about the actual complexity of understanding the relationship between international law and the SDGs, or at least about the limitations of both the SDGs and international law in addressing sustainable development in and of themselves.

Integration is one of the central questions - the 'magic word'12 — pertaining to sustainable development and the respective role of international law. The close interdependence between competing policy goals that need to be pursued in an integrated fashion lies at the core of the concept of sustainable development. Integration in the implementation of the SDGs is a policy goal which also takes on a normative quality. There seems to be no singular meaning of integration, but rather a plurality of norms, principles and (interpretative) tools guiding states' and other actors' policies, "stirring" the law, managing trade-offs and forging synergies across the SGDs.

These different facets of integration manifest themselves prominently in the papers in this special issue. The papers by Verburg \& Waverijn ${ }^{13}$ and Jolly \& Trivedi call for a holistic approach across international legal regimes. Verburg \& Waverijn highlight the need for a holistic approach to international investment law and international trade law, so as to realise the transition to renewable energy. Jolly \& Trivedi argue for pursuing integration of norms and forging synergies across different branches of international law (international refugee law and international human rights law) in order to address climateinduced displacement. Integration is also discussed by way of exploring the interlinkages among the SDGS. Rabinovych explores the interlinkages between

12 Nico Schrijver, The Evolution of Sustainable Development in International Law: Inception, Meaning and Status (Leiden/Boston: Martinus Nijhoff Publishers, 2008) p. 224.

13 Cees Verburg and Jaap Waverijn, 'Liberalizing the Global Supply Chain of Renewable Energy Technology: The Role of International Investment Law in Facilitating Flows of Foreign Direct Investment and Trade' (infra special issue). 
economic development (SDG 8) and the rule of law (SDG 16) and, in particular, economic development and its environmental and social dimensions. Integration is also understood as a means to coordinate, or even consolidate, not only legal regimes but also different actors and scales involved in sustainable development. Mayard critically explores how trade-offs concerning energy infrastructure, environmental protection and social well-being are managed in hydropower projects.

Important questions remain. The (international law) scholarship will only continue to grow, exploring how international law provides opportunities or pose challenges for achieving the SDGs and, conversely, whether the 2030 Agenda contributes to the progressive development of international law. We hope that this special issue makes a modest contribution to this scholarly effort.

The editors of the special issue

Adamantia Rachovitsa \& Marlies Hesselman 